\title{
CNS Pseudallescheria boydii infection
}

\author{
Beuy Joob · Viroj Wiwanitkit
}

Received: 29 December 2014 / Accepted: 6 January 2015 / Published online: 10 January 2015

(C) Belgian Neurological Society 2015

Sir,

The report on CNS Pseudallescheria boydii infection from Turkey by Alpaydın et al. [1] is very interesting. Alpaydın et al. reported a female patient with disseminated Pseudallescheria boydii species complex infection. The patient also has CNS involvement. In fact, Pseudallescheria boydii becomes an important cause of opportunistic mycosis, especially in immunocompromised patients and for those undergoing transplantation [2]. However, the CNS infection by Pseudallescheria boydii can also be seen in immunocompetent host, especially those with the problem of near-drowning [3].

There are many concerns in management of the patient. First, the diagnosis can be easily mistaken. Histologically, very high similarity to Aspergillus spp. can result in misdiagnosis. Second, the treatment of the patients is usually not successful. High fatality rate can be expected. Nevertheless, due to the availability of the new effective antifungal drug voriconazole, the treatment becomes more effective [4]. However, Alapydin et al. reported a case of infection due to Pseudallescheria boydii species complex (not Pseudallescheria boydii). Indeed, this complex comprises many species which might probably display distinct antifungal susceptibility profiles. Due to the increased numbers of immunocomprised hosts, the risk of getting this infection is increased and awareness of this infection, which can lead to early diagnosis and prompt treatment, by practitioner is required.

Conflict of interest None.

\section{References}

1. Alpaydın S, Güler A, Celebisoy N, Polat SH, Turhan T (2014) Pseudallescheria boydii infection of the central nervous system: first reported case from Turkey. Acta Neurol Belg. doi:10.1007/ s13760-014-0391-y

2. Safdar A, Papadopoulos EB, Young JW (2002) Breakthrough Scedosporium apiospermum (Pseudallescheria boydii) brain abscess during therapy for invasive pulmonary aspergillosis following high-risk allogeneic hematopoietic stem cell transplantation. Scedosporiasis and recent advances in antifungal therapy. Transpl Infect Dis 4:212-217

3. Ortmann C, Wüllenweber J, Brinkmann B, Fracasso T (2010) Fatal mycotic aneurysm caused by Pseudallescheria boydii after neardrowning. Int J Legal Med 124:243-247

4. Nesky MA, McDougal EC, Peacock JE Jr (2000) Pseudallescheria boydii brain abscess successfully treated with voriconazole and surgical drainage: case report and literature review of central nervous system pseudallescheriasis. Clin Infect Dis 31:673-677

B. Joob $(\bowtie)$

Sanitation1 Medical Academic Center,

Bangkok 10160, Thailand

e-mail: beuyjoob@hotmail.com

V. Wiwanitkit

Hainan Medical University, Haikou, China 